\title{
Relationships between Maternal Parenting Stress and Reports on Children's Internalizing and Externalizing Problems: A Cross-Lagged Structural Equation Model
}

\author{
Marc Vierhaus ${ }^{1}$, Arnold Lohaus ${ }^{1}$, Anne-Katharina Schmitz ${ }^{1} \&$ Marlene Schoppmeier ${ }^{1}$ \\ ${ }^{1}$ Department of Psychology, Bielefeld University, Bielefeld, Germany \\ Correspondence: Marc Vierhaus, Department of Psychology, Bielefeld University, Bielefeld, Germany. Tel: \\ 49-521-106-4498. E-mail: marc.vierhaus@uni-bielefeld.de
}

Received: November 26, 2012

Accepted: December 25, 2012 Online Published: January 18, 2013

doi:10.5539/jedp.v3n1p39

URL: http://dx.doi.org/10.5539/jedp.v3n1p39

\begin{abstract}
This article presents results of a two-wave panel study with a one-year interval between two time points. The main aim was to examine the reciprocal relationship between parenting stress and reports on problem behavior based on cross-lagged structural equation models. At both time points, adolescents $(\mathrm{M}=12.51$ years on the first time point) and their mothers reported on internalizing and externalizing problem behavior of the adolescents. Additionally, mothers reported on their parenting stress. Independent of grade, mothers of boys report more parenting stress than mothers of girls. Maternal reports on problem behavior are lower than adolescents' self-reports and both reports are correlated with maternal parenting stress. The results of the cross-lagged model comparisons indicate a unidirectional relation between parenting stress and proxy-reports/cross-informant discrepancies regarding adolescent problem behavior: parenting stress appears to be a predictor of proxy reports/cross-informant discrepancies but not vice versa. The results are discussed in terms of a meaningfulness of cross-informant discrepancies.
\end{abstract}

Keywords: parenting stress, cross-informant reports, internalizing problems, externalizing problems

\section{Introduction}

After the transition to parenthood, individuals are confronted with several new demands. In the majority of cases the adoption of the parenting role is experienced as a challenge and often as satisfactory. On the other hand, there are situations where parenting involves distress and the experience of negative emotions. Most of these situations are related to parent-child interactions. In line with this, the most prominent theoretical models of parenting stress by Mash and Johnston (1990) and Abidin (1992) conceptualize the quality of the parent-child interaction as the central source of parenting stress. Both models posit that parenting stress is influenced by characteristics of the child, characteristics of the parents and by characteristics of the environment. While Mash and Johnston (1992) assume direct as well as indirect effects of these characteristics on parenting stress, Abidin (1992) highlights the role of parental appraisals in moderating the relation between potential stressors and parenting stress. He assumes that parenting stress is a result of an individual appraisal process in which a parent assesses the harm of potential stressors through an internal working model of him- or herself as a parent. Thus, whether potential stressors lead to parenting stress depends on an individual's perspective on and an individual's appraisal of events. Based on these fundamental theoretical assumptions, the emphasis of this study is on the relation between maternal parenting stress and characteristics of the child/adolescent. In particular, the focus is on maternal parenting stress because mothers are typically the main primary caregiver for children as well as for adolescents.

First, relevant child characteristics may be objective characteristics (i.e., sex and age). However, the existing literature provides only limited evidence for an effect of the child/adolescent's sex on parenting stress (McBride, Schoppe \& Rane, 2002; Williford, Culkins \& Keane, 2007). If the results of studies support the existence of sex differences (e.g., Scher \& Sharabany, 2005), mothers of boys report more parenting stress than mothers of girls. Results regarding the effect of age (or grade) are poorly documented. Traditionally, research on parenting stress has focused on the transition to parenthood and on early childhood while less is known regarding parenting stress in late childhood or during the transition from childhood to adolescence. This is surprising as it is well-known 
that the parent-child interaction changes from childhood to adolescence. This change is not only characterized by a decreasing frequency of interactions but also by fewer (positive) affective exchanges and more intense conflicts (Collins, Madsen \& Susman-Stillman, 2002; Steinberg \& Silk, 2002) which may be seen as a change in psychological relationship quality. Fortunately, Putnick, Bornstein, Hendricks, Painter, Suwalsky and Collins (2010) conducted a longitudinal study focusing on the transition from childhood to adolescence with two time points (when the children were 10 and again when children were 14 years of age) and assessed paternal as well as maternal parenting stress. Their results show that parenting stress significantly increased between both measurements and displayed high stability (in terms of intra-individual variation).

Second, the relation between parenting stress and subjective (perceived) child characteristics has been addressed by several studies with a focus on internalizing and externalizing problem behavior. Renk, Roddenberry, Oliveros and Sieger (2007) asked 46 mothers to report on their stress experience and on their child's internalizing as well as externalizing problem behavior. Likewise, Costa, Weems, Pellerin and Dalton (2006) report on the relations between parenting stress and parents' proxy reports on internalizing and externalizing problems based on a sample of 300 parents. As in these two studies, Barry, Dunlap, Cotton, Lochman and Wells (2005) used the Child Behavior Checklist (CBCL; Achenbach, 1991) to assess internalizing and externalizing problems whereas Collishaw, Goodman, Ford, Rabe-Hesketh and Pickles (2009) applied the Strengths and Difficulties Questionnaire (SDQ; Goodman 1997) to their sample of parents. At first glance, although the studies differ methodically, they consistently report a positive relation between parenting stress and parents' proxy reports on their children/adolescents' internalizing and externalizing problem behavior.

However, this topic becomes more complicated since problems may not only be reported by parents but just as well by children and adolescents themselves. The research underlines that the aggregation of reports by different informants confronts researchers as well as practitioners with several problems. The reasons are that a) the means of adolescent-reported problems in community samples are consistently higher than the means of parents' proxy reports and that $b$ ) the correlation between both reports seldom exceeds medium size (de los Reyes and Kazdin, 2005). These fundamental results were replicated in several studies thereafter. Some researchers argue that these cross-informant discrepancies may represent the difference in perspective on the same entity. Consequently, studies addressed the relation between parenting stress and cross-informant discrepancies in reports on adolescents' problem behavior. Youngstrom, Loeber and Strouthamer-Loeber (2000) as well as Fung and Lau (2010) reported on parenting stress as a factor positively associated with parent-child disagreement on problem behavior in the transition from childhood to adolescence. The results of both studies indicate that increased parenting stress is associated with increased discrepancies.

Hitherto, there is some general agreement that parenting stress is empirically related to increased proxy reports on problem behavior as well as to increased cross-informant discrepancies. However, the specific role of parenting stress in this relationship has not been identified. Although not entirely, the theoretical models of parenting stress as well as the interpretation of empirical evidence (e.g., Youngstrom et al., 2000) obviously highlight and favor a unidirectional perspective on the relationship. As outlined above, Abidin (1992) conceptualizes parenting stress as a result of a process in which child characteristics or the parent-child interaction are appraised as negative. Therefore, parenting stress can be seen as an outcome of perceived externalizing or internalizing problems of the child (i.e., proxy reports on the child's problems). On the other hand, there is reason to expect a reversed effect of parenting stress on proxy reports on the child's problems. With reference to the depression-distortion hypothesis, Youngstom et al. (2000) interpret their empirical confirmation of the relationship as a rater bias - a systematic influence of psychological distress on parents' evaluations of their child's functioning. From this perspective, increased parental proxy reports on problem behavior is a result of the distress parents experience when interacting with their (adolescent) child. Finally, it seems reasonable to assume a reciprocal relationship between parenting stress and parents' reports on problem behavior as well as cross-informant discrepancies. In this regard, the main purpose of this study is to examine the causal direction in the relationship based on a longitudinal panel study with two time points.

In line with previous studies, Hypothesis 1 states that mothers of boys report more stress than mothers of girls and that maternal parenting stress increases over grades or ages. As can be assumed from the literature on non-clinical samples, Hypothesis 2 expects adolescents to report more internalizing as well as externalizing problems than their mothers. Again in line with previous studies, Hypothesis 3 states that (at both time points) maternal parenting stress is positively related to mothers' proxy reports on internalizing and externalizing problems as well as to respective cross-informant discrepancies. Finally, we assume cross-lagged effects in our panel design. Hypothesis 4: Maternal parenting stress (on time 1) is positively related to proxy reports as well as cross-informant discrepancies regarding internalizing/externalizing problems (on time 2). Hypothesis 5: Proxy 
reports as well as cross-informant discrepancies regarding internalizing/externalizing problems (on time 1) are positively related to maternal parenting stress (on time 2). Hypothesis 6: Maternal parenting stress and proxy reports as well as cross-informant discrepancies regarding internalizing/externalizing problems display a reciprocal relationship (between both time points). The results of the last three Hypotheses may then provide evidence for a causal relationship between the variables.

\section{Methods}

\subsection{Design and Sample}

This study is based on a panel design with a one-year interval between the two time points (May to July in 2010 and 2011). The original sample consisted of $n=281$ mother-adolescent dyads at the first time point. The analyzed sample consisted of $n=185$ German mother-adolescent dyads ( $51.5 \%$ girls) which participated at both time points A comparison of the remaining $29.5 \%$ of the original sample (drop-outs) and the continuous participants regarding the first time point assessments revealed no evidence for a sample selection effect. Of the $n=198$ continuously participating adolescents, $19.7 \%$ were in grade $5,31.3 \%$ were in grade $6,18.7 \%$ were in grade 7 , $21.7 \%$ were in grade 8 and $8.1 \%$ in grade 9 . The mean age of the total sample of adolescents was 12.51 years $(S D=1.42 ; \operatorname{Min}=10 ; \operatorname{Max}=16)$. The participating schools covered a broad range of performance levels and the sample can therefore be seen as largely representative for this age group in Germany. The adolescents' participation in the study was on a voluntary basis and required their parents' permission. All adolescents were Caucasian, from lower to upper middle-class socio-economic backgrounds.

\subsection{Measures}

\subsubsection{Internalizing and Externalizing Problems}

To assess reports of adolescents and reports of their mothers on adolescents' internalizing and externalizing problems the four problem scales of the self-rated and the informant-rated German version of the Strength and Difficulties Questionnaire (SDQ; Klasen et al., 2000) were used. The scales are emotional symptoms (e.g., "I worry a lot"), peer problems (e.g., "I am usually on my own"), conduct problems (e.g., "I fight a lot") and hyperactivity (e.g., "I am easily distracted"). As in the English version, each scale of the German version is represented by five three point scale items (response options: $0=$ "not true", $1=$ "somewhat true" and 2 ="certainly true"). With respect to low-risk samples, Goodman, Lamping and Ploubidis (2010) conclude that the use of SDQ broadband scales of internalizing and externalizing problems instead of the four SDQ problem scales has several advantages (e.g., better discriminant validity). Following this suggestion, in this study the scales emotional symptoms and peer problems were averaged to represent internalizing problems while the scales conduct problems and hyperactivity were averaged to represent externalizing problems. The internal consistencies of the broadband self-report scale internalizing problems are $\alpha_{\text {timel }}=.75$ and $\alpha_{\text {time } 2}=.75$ while they are $\alpha_{\text {timel }}=.77$ and $\alpha_{\text {time } 2}=.79$ based on maternal proxy reports. With respect to the second broadband scale (externalizing problems) the values are $\alpha_{\text {timel }}=.68$ and $\alpha_{\text {time } 2}=.70$ (self-reports) as well as $\alpha_{\text {timel }}=.78$ and $\alpha_{\text {timez }}$ $=.72$ (proxy reports). For further analyses means scores were calculated for all four self-report scales as well as for all four proxy report scales. All internal consistencies are in line with the values reported by Becker, Hagenberg, Roessner, Woerner, and Rothenberger (2004) for the German Version of the SDQ as well as by Goodman et al. (2010) for the English Version of the SDQ. The self-report internalizing and externalizing scales are significantly correlated with $r_{\text {timel }}=.40\left(t_{195}=6.14, p<.001\right)$ and $r_{\text {time } 2}=.31\left(t_{193}=4.49, p<.001\right)$. Also, the proxy report scales are correlated with $r_{\text {timel }}=.42\left(t_{195}=6.54, p<.001\right)$ and $r_{\text {time2 }}=.54\left(t_{194}=8.85, p<.001\right)$. To test the hypotheses related to cross-informant discrepancies, difference scores for internalizing and externalizing problems had to be computed. With reference to Youngstrom et al. (2000) and to be able to compare our results with those of this relevant study, this was done by subtracting the adolescent scale score from the maternal scale separately for the two broadband scales.

\subsubsection{Maternal Parenting Stress}

To assess maternal parenting stress the scale parental stress of the Parental Stress Questionnaire (Domsch \& Lohaus, 2010) was used at each of the two time points. The scale comprises 17 items (e.g. "I struggle a lot with my child" or "There are situations in which I have problems in parenting") with four point scale response options $0=$ "strongly disagree", 1 = "disagree", 2 = "agree" and 3 = "strongly agree"). For further analyses a mean score was calculated. The scale shows a high internal consistency of $\alpha_{\text {timel }}=.94$ and $\alpha_{\text {time } 2}=.91$ which is in line with the value reported in the manual.

\subsection{Data Analyses}

All analyses were done using the statistical software R (Version 2.15.1). Effects of sex and grade (as 
between-subject factors) as well as of informant and time point (as within-subject factors) were analyzed by means of ANOVAs with repeated measures (using the package "ez", version 3.0-1). As recommended by Bakeman (2005), generalized eta-squared $\left(\eta_{G}^{2}\right)$ is reported as the appropriate effect size for repeated measures designs. Relations between variables were analyzed by means of Pearson correlations (using the function cor.test). To analyze the panel data we performed structural equation modeling (using the package "lavaan", version 0.4-14; Roessel, 2012). This was done in four steps: 1) the relation between parenting stress and proxy reports on internalizing problems, 2) the relation between parenting stress and proxy reports on externalizing problems, 3) the relation between parenting stress and cross-informant discrepancies regarding internalizing problems and finally 4) the relation between parenting stress and cross-informant discrepancies regarding externalizing problems. Within each of these analyses steps, the complete cross-lagged structural equation model (Model 4; see Figure 1) was only one of four competing models that were fitted to the data. To test Hypotheses 4 to 6 , several model comparisons had to be undertaken. First, a model without any cross-lagged but with stability paths (path a and path $b$ in Figure 1) was specified (Model 1).

Time point 1

(2010)

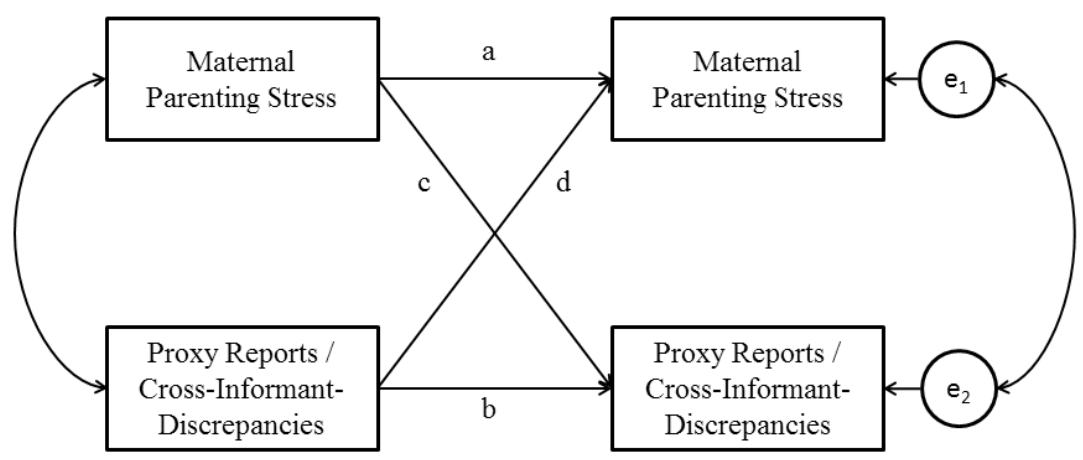

Figure 1. Complete cross-lagged structural equation model relating parenting stress and problem behavior

The fit of this model was compared to that of a Model 2 including an additional cross-lagged structural path from maternal parenting stress at time point 1 to maternal proxy report (in steps 1 and 2) or cross-informant discrepancies (in steps 3 and 4) at time point 2 (path c in Figure 1). It was also compared to Model 3 in which a cross-lagged structural path from maternal proxy report or cross-informant discrepancy regarding internalizing or externalizing problems at time point 1 to maternal parenting stress at time point 2 is specified (path $d$ in Figure 1). Finally, to provide evidence for a causal relationship between maternal parenting stress and proxy-reports as well as cross-informant discrepancies the fit of the complete model (Model 4) had to be compared to the fit of the parsimonious models with only one cross-lagged structural path (Model 2 and Model $3)$.

\section{Results}

First, this section reports on the results related to replication hypotheses. In this regard, results regarding the effects of sex, grade and time point on maternal parenting stress (Hypothesis 1) as well as the effects of sex, grade, informant and time point on maternal proxy reports on children/adolescents' problems (Hypothesis 2) are presented. In addition, this first part of the results section reports on cross-sectional relations between maternal parenting stress and maternal proxy reports as well as cross-informant discrepancies regarding problem reports (Hypothesis 3).

\subsection{Maternal Parenting Stress: Effects of Child's Sex, Grade and Time Point}

In the first Hypothesis it was assumed that maternal parenting stress is higher for mothers of boys than for mothers of girls and that maternal parenting stress increases across grades. To analyze the effect of sex and grade (as between-subject factors) on maternal parenting stress an ANOVA was conducted. Also, the time point was included as within-subject factor. Means and standard deviations are summarized in Table 1. 
Table 1. Means and standard deviations (in parentheses) of maternal parenting stress on time point 1 (t1) and time point $2(\mathrm{t} 2)$

\begin{tabular}{llllll}
\hline \multicolumn{5}{c}{ Boys } & \multicolumn{3}{l}{ Girls } \\
\hline & 5 & $\mathrm{t} 1$ & $\mathrm{t} 2$ & $\mathrm{t} 1$ & $\mathrm{t} 2$ \\
& 5 & $.95(.62)$ & $.90(.63)$ & $.56(.40)$ & $.49(.38)$ \\
Grade $(\mathrm{t} 1)$ & 6 & $.94(.56)$ & $1.07(.74)$ & $.96(.73)$ & $.93(.70)$ \\
& 7 & $.91(.72)$ & $.83(.65)$ & $.64(.70)$ & $.71(.65)$ \\
& 8 & $1.09(.46)$ & $1.07(.56)$ & $.66(.61)$ & $.64(.60)$ \\
& 9 & $1.05(.33)$ & $1.12(.53)$ & $.61(.42)$ & $.57(.34)$ \\
\hline
\end{tabular}

The effect of time point is not significant $\left(F_{1,186}=.13, p=.72, \eta^{2}{ }_{G}<.01\right)$. The results also show that there is no significant main effect of grade $\left(F_{4,186}=1.53, p=.20, \eta^{2}{ }_{G}=.03\right)$ nor an interaction effect between grade and sex $\left(F_{4,186}=.92, p=.45, \eta^{2}{ }_{G}=.02\right)$. However, independent of grade and time point mothers of boys report more maternal parenting stress than mothers of $\operatorname{girls}\left(F_{1,186}=9.61, p=.002, \eta^{2}{ }_{G}=.05\right)$. Thus, Hypothesis 1 is partly confirmed.

\subsection{Internalizing and Externalizing Problems: Effects of Sex, Grade, Informant and Time Point}

The self-reports and mothers' proxy reports are correlated regarding internalizing problems (t1: $r=.39, p<.001$; $\mathrm{t} 2: r=.34, p<.001)$ as well as externalizing problems (t1: $r=.28, p<.001 ; \mathrm{t} 2: r=.27, p<.001)$. Hypothesis 2 is that mothers report more internalizing as well as externalizing problems than adolescents. Separately for both broadband scales an ANOVA with repeated measures was conducted with grade and sex as between-subject factors and time point as well as informant as within-subject factors. Regarding internalizing problems, the results show that the factor informant $\left(F_{1,184}=60.46, p<.001, \eta^{2}{ }_{G}=.07\right)$ and the interaction between informant and sex $\left(F_{1,184}=9.68, p=.002, \eta^{2}{ }_{G}=.01\right)$ have significant effects on problem reports. Both effects $\left(F_{1,184}=60.80\right.$, $p<.001, \eta^{2}{ }_{G}=.08$ and $F_{1,184}=8.53, p=.004, \eta^{2}{ }_{G}=.01$, respectively) could be replicated regarding reports on externalizing problems. Means and standard deviations are depicted in Table 2.

In line with Hypothesis 2, maternal proxy reports display less internalizing as well as less externalizing problems than can be assumed based on the self-reports of their (adolescent) children. Additionally, although a main effect of sex $\left(F_{1,184}=7.85, p=.006, \eta_{G}{ }_{G}=.02\right)$ and a three-way interaction between sex, grade and informant $\left(F_{4,184}=\right.$ $\left.3.00, p=.02, \eta_{G}{ }_{G}=.02\right)$ are significant regarding externalizing problems, it appears that the data structure can be explained much more consistently by the interaction between sex and informant. A closer look at Table 2 indicates that the cross-informant discrepancy between self-report and maternal report is larger for girls than for boys. This interaction effect was not hypothesized but is an interesting result: Mothers of boys appear to report as much internalizing problems as mothers of girls. Assumably, the cross-informant discrepancy is due to the difference between self-reports of girls and boys on their internalizing problems. Contrary, with respect to externalizing problems, self-reports of boys and girls do not appear to differ but there is a difference in the maternal reports about boys' and girls' externalizing problems. Thus, in this case the mean cross-informant discrepancy may be rather due to differences in maternal proxy reports and not in self-reports.

Table 2. Means and standard deviations (in parentheses) of self- and maternal-reported internalizing and externalizing problems on two time points

\begin{tabular}{llllll}
\hline Sex & Grade & Internalizing (SR) & Internalizing (PR) & Externalizing (SR) & Externalizing (PR) \\
\hline Boys & $5(\mathrm{t} 1)$ & $.42(.24)$ & $.39(.39)$ & $.53(.29)$ & $.60(.35)$ \\
& $5(\mathrm{t} 2)$ & $.33(.24)$ & $.39(.38)$ & $.57(.34)$ & $.62(.35)$ \\
& $6(\mathrm{t} 1)$ & $.59(.42)$ & $.33(.29)$ & $.64(.32)$ & $.47(.25)$ \\
& $6(\mathrm{t} 2)$ & $.51(.38)$ & $.43(.31)$ & $.71(.35)$ & $.47(.25)$ \\
& $7(\mathrm{t} 1)$ & $.51(.35)$ & $.28(.26)$ & $.63(.36)$ & $.47(.35)$ \\
& $7(\mathrm{t} 2)$ & $.45(.28)$ & $.24(.21)$ & $.58(.28)$ & $.42(.28)$ \\
& $8(\mathrm{t} 1)$ & $.41(.32)$ & $.41(.31)$ & $.57(.30)$ & $.46(.25)$ \\
\hline
\end{tabular}




\begin{tabular}{llllll}
\hline & $8(\mathrm{t} 2)$ & $.36(.36)$ & $.36(.38)$ & $.51(.28)$ & $.52(.30)$ \\
& $9(\mathrm{t} 1)$ & $.44(.15)$ & $.34(.26)$ & $.66(.24)$ & $.40(.39)$ \\
& $9(\mathrm{t} 2)$ & $.44(.23)$ & $.18(.13)$ & $.48(.23)$ & $.34(.18)$ \\
\hline Girls & $5(\mathrm{t} 1)$ & $.44(.34)$ & $.16(.21)$ & $.57(.31)$ & $.25(.24)$ \\
& $5(\mathrm{t} 2)$ & $.50(.32)$ & $.14(.25)$ & $.62(.38)$ & $.23(.18)$ \\
& $6(\mathrm{t} 1)$ & $.63(.43)$ & $.41(.30)$ & $.69(.34)$ & $.41(.39)$ \\
& $6(\mathrm{t} 2)$ & $.56(.37)$ & $.41(.39)$ & $.56(.26)$ & $.39(.33)$ \\
& $7(\mathrm{t} 1)$ & $.59(.42)$ & $.38(.49)$ & $.57(.28)$ & $.42(.26)$ \\
& $7(\mathrm{t} 2)$ & $.51(.26)$ & $.26(.33)$ & $.59(.27)$ & $.39(.25)$ \\
& $8(\mathrm{t} 1)$ & $.57(.37)$ & $.27(.34)$ & $.54(.25)$ & $.32(.28)$ \\
& $8(\mathrm{t} 2)$ & $.59(.46)$ & $.34(.34)$ & $.50(.30)$ & $.34(.24)$ \\
$9(\mathrm{t} 1)$ & $.62(.27)$ & $.27(.17)$ & $.48(.29)$ & $.24(.23)$ \\
$9(\mathrm{t} 2)$ & $.56(.27)$ & $.29(.20)$ & $.52(.39)$ & $.21(.19)$ \\
\hline
\end{tabular}

Note. $\mathrm{SR}=$ Self-report; $\mathrm{PR}=$ Proxy-report; Grade $=$ Grade on the first time point (t1)

3.3 The Relation between Maternal Parenting Stress and Self- as well as Maternal Reported Internalizing and Externalizing Problems

In line with other studies, Hypothesis 3 assumes that maternal parenting stress is not only related to maternal reports of internalizing and externalizing problems but also to cross-informant discrepancies regarding both scales. Relations at both time points were analyzed by means of Pearson correlations and the results are summarized in Table 3.

Table 3. Relations between maternal parenting stress and proxy-reports as well as cross-informant discrepancies at time point 1 and time point 2

\begin{tabular}{lllll}
\hline & $\begin{array}{l}\text { Internalizing } \\
(\mathrm{PR})\end{array}$ & $\begin{array}{l}\text { Externalizing } \\
(\mathrm{PR})\end{array}$ & $\begin{array}{l}\text { Internalizing } \\
(\mathrm{CID})\end{array}$ & $\begin{array}{l}\text { Externalizing } \\
(\mathrm{CID})\end{array}$ \\
\hline $\begin{array}{l}\text { Maternal } \\
\begin{array}{l}\text { Parenting Stress } \\
\text { (1) }\end{array}\end{array}$ & $.52^{* *}$ & $.63^{* *}$ & $.36^{* *}$ & $.35^{* *}$ \\
$\begin{array}{l}\text { Maternal } \\
\begin{array}{l}\text { Parenting Stress } \\
\text { (t2) }\end{array}\end{array}$ & $.51^{* *}$ & $.65^{* *}$ & $.35^{* *}$ & $.33^{* *}$ \\
\hline
\end{tabular}

Note. $^{* *}=p<.01 ; \mathrm{PR}=$ Proxy-report; CID $=$ Cross-informant discrepancies

First, the results show that maternal parenting stress is related to maternal proxy reports on internalizing problems and externalizing problems on time point 1 as well as on time point 2. Moreover, maternal parenting stress is also related to cross-informant discrepancies regarding internalizing and externalizing problems on both time points. Thus, the results clearly support Hypothesis 3.

Hypotheses 1 to 3 aimed to replicate some fundamental and well documented results regarding maternal parenting stress and cross-informant reports on children/adolescents' problems. Beyond this, the second part of this section presents the results which are based on the cross-lagged structural equation model. The main purpose is to provide some evidence for causality in the relationship between the constructs, which was replicated in the former section.

3.4 Unidirectional and Reciprocal Effects of Maternal Parenting Stress and Cross-informant Reports on Internalizing and Externalizing Problems

As outlined in the introduction, there is good reason to assume unidirectional effects of maternal parenting stress on maternal proxy reports as well as on cross-informant discrepancies (Hypothesis 4) and vice versa (Hypothesis 
5). To address these Hypotheses, comparisons of two unidirectional cross-lagged equation models with a simple stability model were performed. The latter model (Model 1) simply assumes significant path coefficients between the constructs across time points and cross-sectional correlations between the constructs.

Regarding maternal proxy reports on internalizing problems, the fit indices of the stability model (Model 1) are heterogeneous $\left(\mathrm{Chi}^{2}{ }_{2}=9.58, p=.008 ; \mathrm{CFI}=.98, T L I=.95, \mathrm{RMSEA}=.14, \mathrm{SRMR}=.06\right)$ and therefore indicate that cross-lagged effects should be considered. Moreover, compared to Model 2 (with an additional cross-lagged path from maternal parenting stress on time point 1 and problem report on time point 2) its fit is significantly lower $\left(\Delta \mathrm{Chi}^{2}{ }_{1}=9.56, p=.002\right)$. Thus, as assumed in Hypothesis 4 , maternal parenting stress on time point 1 is significantly related to maternal proxy reports on internalizing problems $(\beta=.19, z=3.13, p=.002)$. On the other hand, Model 3 (assuming a cross-lagged path from maternal proxy report on time point 1 and maternal parenting stress on time point 2 ) does not show a better fit than the simple stability model $\left(\Delta c h i^{2}{ }_{1}=.08, p=.78\right)$. This indicates that there is no such unidirectional effect regarding internalizing problems (as assumed in Hypothesis 5). All results regarding the model comparisons and the unidirectional effect assumed regarding all relevant scales are summarized in Table 4.

As can be seen in Table 4, Model 2 is not only confirmed regarding proxy reports on internalizing $\left(\mathrm{Chi}^{2}{ }_{2}=.02, p\right.$ $=.89 ; C F I=1.00, T L I=1.00, R M S E A=.00, S R M R=.00)$ and externalizing problems $\left(C h i^{2}{ }_{2}=1.19, p=.28\right.$; $C F I=1.00, T L I=1.00, R M S E A=.03, S R M R=.02)$. It can also be assumed regarding cross-informant reports on internalizing $\left(\mathrm{Chi}^{2}{ }_{2}=.07, p=.79 ; \mathrm{CFI}=1.00, T L I=1.00, \mathrm{RMSEA}=.00, \mathrm{SRMR}=.00\right)$ as well as on externalizing problems $\left(\mathrm{Chi}^{2}{ }_{2}=2.39, p=.12 ; \mathrm{CFI}=1.00, T L I=.98, \mathrm{RMSEA}=.09, \mathrm{SRMR}=.02\right)$. Thus, the results consistently support the assumption that maternal parenting stress increases reports on internalizing and externalizing problems as well as cross-informant discrepancies regarding both problem scales (assumed in Hypothesis 4). On the other hand, there is no such evidence for a reverse effect (which was assumed in Hypothesis 5).

Table 4. Model fit and comparison statistics regarding unidirectional effects between maternal parenting stress and parents' proxy reports as well as cross-informant discrepancies

\begin{tabular}{lrrlrrrr}
\hline Model & Chi & $d f$ & Comparison & $\Delta C h i^{2}$ & $\Delta d f$ & $\beta$ & $p$ \\
\hline Internalizing & & & & & & & \\
\hline Stability (M1) & 9.58 & 2 & & & & & \\
Unidirectional (M2) & 0.02 & 1 & M1 vs. M2 & $9.56^{* * *}$ & 1 & .19 & .002 \\
Unidirectional (M3) & 9.51 & 1 & M1 vs. M3 & .08 & 1 & .01 & .78 \\
\hline Externalizing & & & & & & & \\
\hline Stability (M1) & 18.47 & 2 & & & & & \\
Unidirectional (M2) & 11.20 & 1 & M1 vs. M2 & $7.27^{* * *}$ & 1 & .25 & $<.001$ \\
Unidirectional (M3) & 18.47 & 1 & M1 vs. M3 & .00 & 1 & .00 & .95 \\
\hline CID Internalizing & & & & & & & \\
\hline Stability (M1) & 5.48 & 2 & & & & & \\
Unidirectional (M2) & 0.07 & 1 & M1 vs. M2 & $5.41^{*}$ & 1 & .15 & .02 \\
Unidirectional (M3) & 5.47 & 1 & M1 vs. M3 & .01 & 1 & .01 & .91 \\
\hline CID Externalizing & & & & & & & \\
\hline Stability (M1) & 7.59 & 2 & & & & & \\
Unidirectional (M2) & 2.39 & 1 & M1 vs. M2 & $5.20^{*}$ & 1 & .15 & .02 \\
Unidirectional (M3) & 5.64 & 1 & M1 vs. M3 & 1.95 & 1 & .06 & .16 \\
\hline
\end{tabular}

Note. Stability (M1) = Model with stability paths only; Unidirectional (M2) = Model with an additional cross-lagged path from maternal parenting stress to problem reports; Unidirectional $(\mathrm{M} 3)=$ Modell with additional an additional cross-lagged path from problem reports to maternal parenting stress; CID = Cross-informant discrepancies 
To complete this section, the verified unidirectional model (M2) was compared to a complete cross-lagged model (M4) which assumes stability paths as well as two cross-lagged paths (which were separately assumed in the unidirectional models). An insignificant result would indicate that the parsimonious model M2 should be preferred to the complete model (M4). The $C h i^{2}$-difference statistics show that the assumption of M2 holds regarding proxy reports on internalizing $\left(\Delta c h i^{2}{ }_{1}=.02, p=.89\right)$ and externalizing problems $\left(\Delta c h i^{2}{ }_{1}=1.19, p=.28\right)$ as well as regarding cross-informant discrepancies in reports on internalizing $\left(\Delta c h i^{2}{ }_{1}=.07, p=.79\right)$ and externalizing problems $\left(\Delta c h i^{2}{ }_{1}=2.29, p=.12\right)$. Thus, these results do not confirm the assumption of a bidirectional causal relation between maternal parenting stress and proxy reports or cross-informant discrepancies (Hypothesis 6).

\section{Discussion}

Besides characteristics of the parent and the environment, parenting stress may be influenced by characteristics of the child (Abidin, 1992; Mash \& Johnston, 1990), which can either be objective (like sex or grade) or subjective (like proxy reports on the child's problem behaviour). With respect to the objective characteristics, results are rather heterogeneous or sparsely found in studies focusing on middle or late childhood and adolescence. However, some empirical evidence exists that mothers of boys report more parenting stress than mothers of girls and that parenting stress increases during the transition from childhood to adolescence. The results of the present study confirm the sex difference but do not support the effect of grade. This, however, fits in with the existing heterogeneous literature on parenting stress and it appears that there may be no general effects of both objective child characteristics. Whether sex differences or age/grade differences are found may be due to different methodological approaches pursued in the relevant studies (e.g., different instruments for the assessment of parenting stress). On the other hand, according to Abidin (1992) the individual appraisal process of parents may moderate the relation between objective characteristics and parenting stress. Thus, it can be assumed that gender-role expectations of parents regarding the behavior of their child rather than the biological sex of the child itself may be predictive for parenting stress. However, to date, no study has addressed this question.

The results of the present study regarding the cross-informant reports on adolescent internalizing and externalizing problem behavior support that (in a non-clinical sample) on average mothers report significantly less problems than their adolescent child. Additionally, the correlations between self-reports and maternal reports are medium sized. Based on a substantial number of previous studies (for an overview see de los Reyes \& Kazdin, 2005), these results were to be expected, although the reasons for these discrepancies with regard to means and correlations are not yet revealed. One factor which has been focused by several studies but was heterogeneously confirmed by their results is the role of the child/adolescent's sex. In this regard, the results of the present study shed light on an interesting interaction between sex and informant: Sex differences in internalizing problems appear only in adolescents' self-reports (with higher means for girls than for boys) whereas sex differences in externalizing behavior are restricted to maternal reports (with higher means for boys than for girls). This raises the question whether cross-informant discrepancies may partly result because mothers have differential expectations about who displays externalizing behavior (e.g., boys rather than girls) but not about who displays internalizing behavior (e.g., girls as well as boys) whereas adolescent girls and boys differ in their self-reports regarding internalizing but not regarding externalizing behavior. Thus, one possible factor underlying cross-informant discrepancies may be the gender-role expectations of informants regarding emotional and behavioral problems. Recently, Schmitz, Vierhaus and Lohaus (2012) could show that adolescent boys and girls expect more sex differences in coping strategies than actually exist. Moreover, in their study adolescents' reports on internalizing as well as externalizing problem behavior could be predicted by their gender role expectations on whether boys or rather girls make use of several coping strategies (e.g., aggressive action or giving up). In light of the results of the present study, it can be assumed that respective results could be obtained regarding parental reports on their gender-specific expectations and adolescent problem behavior.

The relation between parenting stress and child/adolescent problem behavior has been widely investigated by a simple correlational approach (Martin, Ford, Dyer-Friedmann, Tang \& Huffman, 2004) and the results of the present study corroborate the existence of correlations between parenting stress and maternal reported problem behavior as well as cross-informant discrepancies. However, as correlations are not interpretable in terms of causality the design and the analyses of the present study went beyond this simple correlation approach. As a result, the main question that could be addressed using a cross-lagged structural equation model was whether the experience of parenting stress increases the amount of reported problem behavior or whether the amount of experienced problem behavior increases parenting stress. As outlined in the Introduction, this comparison reflects two theoretically based perspectives on the relationship of both constructs. Interestingly, the results do 
not support a reciprocal causal relationship. Instead, regarding all relevant variables they consistently provide evidence for the first possible causality: the more parenting stress is experienced by mothers of adolescent children the more problem behavior is reported by the mother and the more discrepancy exists between the report of the mother and the report of the adolescent child. Thus, these is the first study which results underline the assumption (e.g., Youngstrom et al., 2000) of an effect of parenting stress on proxy-reports on problem behavior and respective cross-informant discrepancies.

Of course, this central result regarding causality needs to be replicated by future studies. However, it seems to corroborate the assumption that the relation between maternal affectivity and proxy-reports on adolescent problems reflects a more general phenomenon than is described in the depression-distortion hypothesis (Chilcoat \& Breslau, 1997; Youngstrom et al., 2000). Originally, this hypothesis states that depressive symptoms of parents lead to an over-report on adolescent problems because of a mood-congruent bias in the recall of parents. Thus, it claims depression to be a cause for over-reports and cross-informant discrepancies. Indeed, although early studies suffered from methodological drawbacks, more recent studies using a more appropriate methodological approach supported the hypothesis (e.g., Gartstein, Bridgett, Dishion \& Kaufman, 2009). However, some results query the specificity of the influence of depression on informants' reports on adolescent problems such as those reported by Briggs-Gowan, Carter and Schwab-Stone (1996). In this study maternal depressive symptoms and anxiety symptoms shared variance in explaining proxy-reports as well as cross-informant reports, but only anxiety (and not depression) explained unique variance. Thus, the authors claim that the influence of other aspects of parents' affectivity besides depression on maternal reports may be obscured. And based on the results of the present study, one of these factors appears to be parenting stress, which may reflect a broader scope of negative affectivity.

Some recommendations regarding theory and directions for future research should be drawn based on the results of the current study. De los Reyes and Kazdin (2005) conclude that discrepancies in cross-informant reports can be regarded as one of the most robust findings in the literature on developmental psychology and developmental psychopathology. It has been argued that parents' proxy-reports on adolescents' emotional and behavioral problems may provide unique information which cannot be obtained via the adolescents' own self-reports (Achenbach, 2005; Vierhaus \& Lohaus, 2007). The idiosyncratic perspective of parents on their (adolescent) child, on his or her emotional experiences or problematic behaviors is related to parenting behavior (e.g., Berger, Jodl, Allen \& Mc Elhaney Davidson, 2005) and also to the self-image of the adolescent (e.g., Snyder, Cramer, Afrank \& Patterson, 2005). However, the results of the present study indicate that such relations may be unidirectional. Regarding parenting stress, it appears that the amount of problematic behaviors reported by the parents is influenced by their experience of parenting stress. Thus, in light of the results of the present study, parenting stress appears to be more than a corollary of different perspectives on the problems of the child. Rather, parenting stress may be seen as a catalyst of parents' reports on the problems of the child. Future studies on cross-informant discrepancies may therefore try to incorporate aspects of the psychological parent-child relationship quality besides objective and subjective characteristics of the child or of the parents. This research, however, needs to be directed by a theoretical framework which should also build on family systems based theories such as the family stress model (Conger, Conger \& Martin, 2010). Regarding this framework, different aspects of the parent-child relationship quality should specifically underlie and influence factors like perspective and attribution processes of informants which are fundamental factors in the Attribution Bias Context Model proposed by de los Reyes and Kazdin (2005) to explain cross-informant discrepancies.

De los Reyes (2011) states that answers to the question whether informant disagreement is meaningful should further provide recommendations how this meaningfulness may be (practically) useful. Indeed, the unidirectional perspective on the relation between parenting stress and reports on adolescent problems which is consistently underlined by the results of the present study may have practical implications. Both parenting stress and perceptions on adolescent problem behavior are central aspects of family-oriented interventions. As a consequence, a comprehensive understanding of their relation may aid interventions. The perspective of parents on the (problematic) behavior of their child is related to their parenting behavior which may in turn influence the behavior of the child. The results of the current study clearly indicate that this vicious circle may be interrupted if family-oriented interventions especially focus the stress parents experience during the daily interactions with their child. Many existing programs rather try to foster parenting competences or to modify parental cognitions (Sanders, 1999). Evaluations of these programs provide evidence for positive effects (Nowak \& Heinrichs, 2005). However, a strong moderator of the effectiveness is the degree to which families are initially distressed with higher effects for more distressed families. As a consequence, practitioners focus on parenting stress and thus may emphasize a reduction of the experienced stress of parents. Thus, fostering emotional well-being of parents 
may be a key variable for family-oriented interventions.

\section{References}

Abidin, R. R. (1992). The determinants of parenting behaviour. Journal of Clinical Child Psychology, 21, 407-412. http://dx.doi.org/10.1207/s15374424jccp2104_12

Achenbach, T. M. (1991). Manual for the Child Behavior Checklist/4-18 and 1991 Profile. University of Vermont Department of Psychiatry. Burlington, VT.

Achenbach, T. M. (2005). Assessment of adult psychopathology: Meta-analyses and implications of cross-informant correlations. Psychological Bulletin, 131, 361-382. http://dx.doi.org/10.1037/0033-2909.131.3.361

Bakeman, R. (2005). Recommended effect size statistics for repeated measures designs. Behavior Research Methods, 37, 379-384. http://dx.doi.org/10.3758/BF03192707

Barry, T. D., Dunlap, S. T., Cotton, S. J., Lochman, J. E., \& Wells, K. C. (2005). The influence of maternal stress and distress on disruptive behavior problems in boys. Journal of American Academy of Child and Adolescent Psychiatry, 44, 265-273. http://dx.doi.org/10.1097/00004583-200503000-00011

Becker, A., Hagenberg, N., Roessner, V., Woerner, W. \& Rothenberger, A. (2004). Evaluation of the self-reported SDQ in a clinical setting: Do self-reports tell us more than ratings by adult informants? European Child \& Adolescent Psychiatry, 13, 17-24. http://dx.doi.org/10.1007/s00787-004-2004-4

Berger, L. E., Jodl, K. M., Allen, J. P., \& McElhaney Davidson, B. (2005). When adolescents disagree with others about their symptoms: Differences in attachment organization as an explanation of discrepancies between adolescent-, parent-, and peer-reports of behavior problems. Development and Psychopathology, 17, 509-528. http://dx.doi.org/10.1017/S0954579405050248

Briggs-Gowan, M. J., Carter, A. S., \& Schwab-Stone, M. (1996). Discrepancies among mother, child, and teacher reports: Examining the contributions of maternal depression and anxiety. Journal of Abnormal Child Psychology, 24, 749-765. http://dx.doi.org/10.1007/BF01664738

Chilcoat, H. D., \& Breslau, N. (1997). Does psychiatric history bias mother's reports? An application of a new analytic approach. Journal of the American Academy of Child and Adolescent Psychiatry, 36, 971-979. http://dx.doi.org/10.1097/00004583-199707000-00020

Collins, W. A., Madsen, S. D., \& Susman-Stillman. (2002). Parenting during middle childhood. In M.H. Bornstein (Ed.), Handbook of parenting (Vol. 1): Children and parenting (pp. 73-101). Mahwah, NJ: Erlbaum.

Collishaw, S., Goodman, R., Ford, T., Rabe-Hesketh, S., \& Pickles, A. (2009). How far are associations between child, family and community factors and child psychopathology informant-specific and informant-general? The Journal of Child Psychology and Psychiatry, 50, 571-580. http://dx.doi.org/10.1111/j.1469-7610.2008.02026.x

Conger, R. D., Conger, K. J., \& Martin, M. J. (2010). Socioeconomic status, family processes, and individual $\begin{array}{lllll}\text { development. Journal of Marriage and Family, } & \text { 72, 685-704. }\end{array}$ http://dx.doi.org/10.1111/j.1741-3737.2010.00725.x

Costa, N. M., Weems, C. F., Pellerin, K., \& Dalton, R. (2006). Parenting stress and childhood psychopathology: An examination of specificity to internalizing and externalizing symptoms. Journal of Psychopathology and Behavioral Assessment, 28, 113-122. http://dx.doi.org/10.1007/s10862-006-7489-3

De los Reyes, A. (2011). Special section: more than measurement error: Discovering meaning behind discrepancies in clinical assessments of children and adolescents. Journal of Child and Adolescent Psychology, 40, 1-9. http://dx.doi.org/10.1080/15374416.2011.533405

De los Reyes, A., \& Kazdin, A. E. (2005). Informant discrepancies in the assessment of childhood psychopathology: A critical review, theoretical framework, and recommendations for further study. Psychological Bulletin, 131, 483-509. http://dx.doi.org/10.1037/0033-2909.131.4.483

Domsch, H., \& Lohaus, A. (2010). Elternstressfragebogen (ESF) [Parental Stress Questionnaire]. Göttingen: Hogrefe.

Fung, J. J., \& Lau, A. (2010). Factors associated with parent-child (dis)agreement on child behavior and parenting problems in Chinese immigrant families. Journal of Clinical Child \& Adolescent Psychology, 39, 


\section{4-327. http://dx.doi.org/10.1080/15374411003691693}

Gartstein, M. A., Bridgett, D. J., Dishion, T. J., \& Kaufman, N. K. (2009). Depressed mood and maternal report of child behavior problems: Another look at the depression-distortion hypothesis. Journal of Applied Developmental Psychology, 30, 149-160. http://dx.doi.org/10.1016/j.appdev.2008.12.001

Goodman, A., Lamping, D. L., \& Ploubidis, G. B. (2010). When to use broader internalising and externalising subscales instead of the hypothesised five subscales on the Strengths and Difficulties Questionnaire (SDQ): Data from British parents, teachers and children. Journal of Abnormal Child Psychology, 38, 1179-1191. http://dx.doi.org/10.1007/s10802-010-9434-x

Goodman, R. (1997). The Strengths and Difficulties Questionnaire: A research note. Journal of Child Psychology and Psychiatry, 38, 581-586. http://dx.doi.org/10.1111/j.1469-7610.1997.tb01545.x

Klasen, H., Woerner, W., Wolke, D., Meyer, R., Overmeyer, S., Kaschnitz, W., Rothenberger, A., \& Goodman, R. (2000). Comparing the German versions of the Strengths and Difficulties Questionnaire (SDQ-Deu) and the Child Behavior Checklist. European Child and Adolescent Psychiatry, 9, 271-276. http://dx.doi.org/10.1007/s007870070030

Mash, E. J., \& Johnston, C. (1990). Determinants of parenting stress: Illustrations from families of hyperactive children and families of physically abused children. Journal of Clinical Child Psychology, 19, 313-328. http://dx.doi.org/10.1207/s15374424jccp1904_3

Martin, J. L., Ford, C. B., Dyer-Friedmann, J., Tang, J., \& Huffman, L. C. (2004). Patterns of agreement between parent and child ratings of emotional and behavioral problems in an outpatient clinical setting: When children endorse more problems. Developmental and Behavioral Pediatrics, 25, 150-155. http://dx.doi.org/10.1097/00004703-200406000-00002

McBride, B. A., Schoppe, S. J. \& Rane, T. R. (2002). Child characteristics, parenting stress, and parental involvement: Fathers versus mothers. Journal of Marriage and Family, 64, 998-1011. http://dx.doi.org/10.1111/j.1741-3737.2002.00998.x

Nowak, C., \& Heinrichs, N. (2005). A comprehensive meta-analysis of Triple P-Positive Parenting Program using hierarchical linear modeling: Effectiveness and moderating variables. Journal of Clinical Child and Family Psychology Review, 11, 114-144. http://dx.doi.org/10.1007/s10567-008-0033-0

Putnick, D. L., Bornstein, M. H., Hendricks, C., Painter, K. M., Suwalsky, J. T. D., \& Collins, W. A. (2010). Stability, continuity, and similarity of parenting stress in European American mothers and fathers across their child's transition to adolescence. Parenting: Science and practice, 10, 60-77. http://dx.doi.org/10.1080/15295190903014638

Renk, K., Roddenberry, A., Oliveros, A., \& Sieger, K. (2007). The relationship of maternal characteristics and perceptions of children to children's emotional and behavioral problems. Child \& Family Behavior Therapy, 29, 37-57. http://dx.doi.org/10.1300/J019v29n01_03

Rosseel, Y. (2012). Lavaan: An R package for structural equation modelling. Journal of Statistical Software, 48, 1-36. Retrieved from http://www.jstatsoft.org/v48/i02/paper

Sanders, M. R. (1999). Triple P - Positive Parenting Program: Towards an empirically validated multi-level parenting and family support strategy for the prevention and treatment of child behavior and emotional problems. Child and Family Psychology Review, 2, 71-90. http://dx.doi.org/10.1023/A:1021843613840

Scher, A., \& Sharabany, R. (2005). Parenting anxiety and stress: Does gender play a part at 3 months of age? Journal of Genetic Psychology, 166, 203-213. http://dx.doi.org/10.3200/GNTP.166.2.203-214

Schmitz, A.-K., Vierhaus, M., \& Lohaus, A. (2012). Geschlechtstypische Unterschiede und geschlechtstypische Erwartungen beim Einsatz von Bewältigungsstrategien und ihre Zusammenhänge zum Problemverhalten von Jugendlichen [Sex differences and sex-related expectancies regarding the use of coping strategies and their relations to adolescents' problem behavior]. Zeitschrift fuer Gesundheitspsychologie, 20, 13-21. http://dx.doi.org/10.1026/0943-8149/a000060

Snyder, J., Cramer, A., Afrank, J., \& Patterson, G. (2005). The contribution of ineffecitve discipline and parental hostile attributions of child misbehavior to the development of conduct problems at home and school. Developmental Psychology, 41, 30-41. http://dx.doi.org/10.1037/0012-1649.41.1.30

Steinberg, L., \& Silk, J. S. (2002). Parenting adolescents. In: M.H. Bornstein (Ed.), Handbook of Parenting (Vol. 1): Children and Parenting (pp. 103-133). Mahwah, NJ: Erlbaum. 
Vierhaus, M., \& Lohaus, A. (2008). Children and parents as informants of emotional and behavioural problems predicting female and male adolescent risk behaviour: A longitudinal cross-informant study. Journal of Youth and Adolescence, 37, 211-224. http://dx.doi.org/10.1007/s10964-007-9193-3

Williford, A. P., Calkins, S. D., \& Keane, S. P. (2007). Predicting change in parenting stress across early childhood: Child and maternal factors. Journal of Abnormal Child Psychology, 35, 251-263. http://dx.doi.org/10.1007/s10802-006-9082-3

Youngstrom, E., Loeber, R., \& Stouthamer-Loeber, M. (2000). Patterns and correlates of agreement between parent, teacher, and male adolescent ratings of externalizing and internalizing problems. Journal of Consulting and Clinical Psychology, 68, 1038-1050. http://dx.doi.org/10.1037/0022-006X.68.6.1038 